\title{
OBIS-SEAMAP: developing a biogeographic research data commons for the ecological studies of marine mammals, seabirds, and sea turtles
}

\author{
P. N. Halpin ${ }^{1, *}$, A. J. Read $^{2}$, B. D. Best ${ }^{1}$, K. D. Hyrenbach ${ }^{2}$, E. Fujioka ${ }^{1}$, M. S. Coyne ${ }^{1}$, \\ L. B. Crowder ${ }^{2}$, S. A. Freeman ${ }^{2}$, C. Spoerri ${ }^{1}$ \\ ${ }^{1}$ Marine Geospatial Ecology Laboratory, Duke University, Durham, North Carolina 27708, USA \\ ${ }^{2}$ Duke University Marine Laboratory, Beaufort, North Carolina 28516, USA
}

\begin{abstract}
Our ability to understand, conserve, and manage the planet's marine biodiversity is fundamentally limited by the availability of relevant taxonomic, distribution, and abundance data. The Spatial Ecological Analysis of Marine Megavertebrate Animal Populations (SEAMAP) initiative is a taxon-specific geo-informatics facility of the Ocean Biogeographic Information System (OBIS) network. OBIS-SEAMAP has developed an expanding geo-database of marine mammal, seabird, and sea turtle distribution and abundance data globally. The OBIS-SEAMAP information system is intended to support research into the ecology and management of these important marine megavertebrates and augment public understanding of the ecology of marine megavertebrates by: (1) facilitating studies of impacts on threatened species, (2) testing hypotheses about biogeographic and biodiversity models, and (3) supporting modeling efforts to predict distributional changes in response to environmental change. To enhance the research and educational applications of this database, OBIS-SEAMAP provides a broad array of web-based products and services, including rich species profiles, compliant metadata, and interactive mapping services. This system takes advantage of recent technological advances in Geographic Information Systems (GIS), Internet data standards, and content management systems to stimulate a novel community-based approach to the development of a data commons for biogeographic and conservation research. To date, the global OBISSEAMAP database includes $>1$ million observation records from 163 datasets, spanning 71 yr (1935 to 2005) provided by a growing international network of data providers.
\end{abstract}

KEY WORDS: Biogeography $\cdot$ Marine mammals $\cdot$ Seabirds $\cdot$ Sea turtles $\cdot$ Oceanography $\cdot$ Spatial ecology $\cdot$ GIS $\cdot$ Ecoinformatics $\cdot$ OBIS

\section{INTRODUCTION}

\section{Objectives}

Understanding biogeographic patterns in marine systems requires integrating data from many disparate disciplines (e.g. systematics, ecology, oceanography) gathered over multiple temporal scales (e.g. seasons, years, decades) (McGowan 1990, NRC 1996, PierottBults 1997). In 1997, the Alfred P. Sloan Foundation, in conjunction with the National Oceanographic Partnership Program (NOPP), initiated the ambitious $10 \mathrm{yr}$
'Census of Marine Life' (CoML) to enhance the biogeographic and ecological understanding and appreciation of marine biodiversity (Ausubel 1999). This initiative seeks to answer 3 basic questions: What used to live in the sea? What currently lives in the sea? And what will live in the sea? The CoML program includes the Scientific Committee on Oceanic Research New Technologies Working Group, which communicates awareness of advanced technologies supporting the CoML efforts and of 4 related program areas: (1) the History of Marine Animal Populations (HMAP), a synthesis of historical marine biodiversity data during the 
last $500 \mathrm{yr}_{\text {; }}$ (2) CoML pilot field projects, designed to test and implement novel sampling technologies; (3) the Ocean Biogeographic Information System (OBIS), an initiative to provide global, species-level, geo-referenced biogeographic data; and (4) the Future of Marine Animal Populations (FMAP) initiative, a modeling effort to determine changes in biodiversity and species distributions in response to anthropogenic impacts and climate change (Decker \& O'Dor 2002). The information system role of OBIS provides a critical bridge between historic mapping, new field projects, and future modeling efforts. A recent baseline report entitled 'The Unknown Ocean' provides an assessment of the known, unknown, and unknowable in the global ocean, and summarizes the challenges and opportunities that lay ahead for the CoML program (O'Dor 2003).

A necessary first step when compiling a global baseline of marine biodiversity entails the creation of OBIS to compile, store, package, and disseminate georeferenced biological and physical information to a broad array of users worldwide. While OBIS was envisioned as the repository of existing digital biogeographic datasets, including those originating from CoML field projects, the recent development of powerful web-based informatics and mapping tools has vastly expanded the potential research and educational applications of this initiative (Alldredge et al. 1999, Grassle \& Stocks 1999).

Perhaps the most innovative aspect of the OBIS system is the planned comprehensive perspective of marine ecosystems it encompasses, by integrating information on physical properties (e.g. ocean temperature), ocean productivity patterns (e.g. chlorophyll a concentration), mid-trophic-level organisms (e.g. fish and squid), and top predators (e.g. large predatory fishes, marine mammals, seabirds, sea turtles). This integrative approach will enhance our understanding of which physical-biological mechanisms structure marine ecosystems, by providing simultaneous information about bottom-up (e.g. productivity) and topdown (e.g. predation) regulation of marine food webs. In addition to addressing the way entire ecosystems are structured and respond to oceanographic variability, the OBIS system will help assess the magnitude of anthropogenic impacts on marine systems. In particular, an understanding of the way marine organisms are influenced by biological and physical properties will delineate the critical habitats of protected species, and will help interpret apparent changes in population abundance by placing them in a broader oceanographic and climatic context.

The OBIS-SEAMAP program has developed an operational prototype system for the integration of oceanographic information with animal observation data. Similar systems and functionality are planned for the larger OBIS network.
Participants at CoML planning workshops repeatedly emphasized the importance of including upper-trophic marine predators in this initiative, due to their conservation status and their critical role as ecosystem-level indicators (Bradley 1999, Levi et al. 1999). In particular, the recent development of miniaturized telemetry and archival tagging technologies has facilitated the use of marine megavertebrates as autonomous sampling platforms of the marine environment, whereby researchers can integrate fine-scale behavioral information (e.g. diving) with physical environmental data (e.g. water temperature) (Stone et al. 1999). The ability to sample the 3-dimensional environment where marine megavertebrates forage at the appropriate spatial and temporal scales is providing revolutionary insights into the way these animals make a living, and is helping to delineate important migration and foraging grounds (Block et al. 2003, Welch et al. 2003).

Principal investigators at Duke University, in conjunction with a consortium of international partners, initiated the Spatial Ecological Analysis of Megavertebrate Animal Populations (OBIS-SEAMAP) initiative in 2002. The aim of this project was to assemble a global geo-referenced data repository for marine mammals, birds, and turtles, as part of the OBIS initiative. This publicly available biogeographic resource includes at-sea and colonybased absolute counts and standardized metrics of relative abundance, standardized metadata describing survey and data-processing methods, and species profiles with detailed ecological and taxonomic information.

\section{Development of a data commons}

The creation of a data commons for biogeographic and conservation research is only feasible when a sense of community exists amongst researchers, data holders, administrators, and the users of such a system. Sufficient benefits must be provided to encourage the different participants to join the community. Most researchers involved in biodiversity informatics programs recognize their value as a way to expand future scientific inquiry into questions of a spatial and temporal scope larger than any individual researcher can currently tackle in isolation. Nevertheless, the enhanced ability to seek novel scientific questions fueled by the availability of larger datasets may not suffice to stimulate some reticent data providers into contributing their data holdings. Rather, these reluctant participants may need more tangible and specific rewards. OBIS-SEAMAP has been developed with this in mind, and includes a wide array of attractive tools and services to the research and conservation communities. More specifically, to enroll data providers into the system we have devised 3 types of services: 
(1) 'data management', (2) 'value added', and (3) 'community development'.

Data management services are designed to facilitate the integration of the various datasets into the OBISSEAMAP database, by assisting with quality assurance and quality control (e.g. speed filters to identify erroneous locations along a survey track), dissemination (e.g. tools to share and disseminate research results with colleagues and founders), information technology benefits (e.g. data back-up in the OBIS-SEAMAP server), and advertising (e.g. high visibility of individual datasets and supporting citations on the public OBIS-SEAMAP website as well as the OBIS portal and other metadata clearinghouses).

Value added services enrich the datasets contributed to OBIS-SEAMAP in a variety of ways, which can include providing additional ancillary data (e.g. automatic integrated taxonomic information system, a taxonomic hierarchy for species recorded in contributed datasets), developing metadata to enhance the longterm use of the data (e.g. automated creation of mandated Federal Geographic Data Committee [FGDC]; www.fgdc.gov/clearinghouse/clearinghouse.html metadata), and merging the biogeographic information with additional environmental datasets (e.g. assigning remotely sensed environmental conditions from satellites to sightings in a given dataset).

Community development services include the OBISSEAMAP web tools designed to give data providers and users the ability to add content to the site (e.g. users have their own page and can post news items and announcements for public viewing), the right to manage their own datasets (e.g. a data provider can add or remove public access to a given dataset by clicking a button in a private 'mydata' page), formation of a supervising steering committee of highly respected community members, and broad exposure to the public (e.g. each dataset features links to the data provider contact pages, and includes relevant citations of published papers). In addition, users can provide access to groups of colleagues to promote collaborative efforts. To further nurture the sense of community, OBIS-SEAMAP has engaged the broader community of data providers and system users through a series of outreach activities. Namely, we have organized annual meetings with data providers and steering committee members, and have made presentations at international scientific meetings (e.g. in the fields of oceanography and of taxon-specific and geo-informatics), as well as meetings of potential user groups (e.g. marine educators, resource managers).

A critical aspect in the process of nurturing a sense of community entails addressing the concerns and needs of data providers at the onset of system design. An awareness of the apprehensions about data sharing is critical for effective system development. The best way to reconcile these disparate perspectives is for individuals to participate in the process through multiple roles. For instance, by contributing their own data to the system, the OBIS-SEAMAP developers have confronted the same proprietary (e.g. crediting funders) and scientific (e.g. ensuring faithful representation of the data) issues faced by other providers. This mutual understanding, facilitated by the trusted and personal connection between system developers and data providers, has been essential when devising approaches to protect proprietary data rights and to manage data access by the public and the scientific community.

OBIS-SEAMAP has developed terms of data use which protect the rights of data contributors without restricting the applicability of the system for a wide array of educational and conservation applications (http://seamap.env.duke.edu/about/termsofuse). All data are made available as whole datasets, with full citation and contact information from the original data providers. Complete metadata and the terms of use are bundled with the download of datasets to further promote responsible usage and proper citation.

As ecological research becomes increasingly global in scope and data intensive, biodiversity informatics programs will need to reconcile diverse national and international data access issues in a systematic fashion and in a policy arena that transcends national jurisdictions (Arzberger et al. 2004). As a data aggregator at this global scale, OBIS-SEAMAP will continue to adapt to modern 'community development' approaches and encourage good practices by others in this field.

\section{INFORMATION SYSTEM DEVELOPMENT}

The OBIS-SEAMAP system provides a wide variety of products, designed to meet the diverse needs of educators, students, resource managers, and researchers interested in marine biogeography. In particular, the web-based GIS applications make the OBIS-SEAMAP datasets widely accessible to students, researchers in less developed countries, and other users without access to expensive desktop GIS programs.

The tools used for storing, distributing, and visualizing data in OBIS-SEAMAP leverage existing software, standards, and initiatives. Specific technologies evolve rapidly, but because the framework used by OBIS-SEAMAP relies on open-standards and open-source products, the system can adapt quickly. Some of the most attractive aspects of these open-source technologies include their low cost, standards compliance, reusability, and customizable nature. The use of open standards, such as the Open GIS Consortium (OGC) standards, is especially important to promote the usage and interoperability of marine animal observation data between different software platforms and web service applications. 


\section{Overall strategy and thematic focus}

The scope of this project has required engaging a wide array of stake-holders, including owners of existing datasets, the research community, and the general public. An aggressive outreach program has been undertaken to attract potential data providers and system users by: (1) providing tools and services to data providers, (2) building and maintaining an online data archive, and (3) demonstrating the utility of the system through new research. More specifically, a series of potential applications has been devised to help illustrate the utility of the OBIS-SEAMAP system for biogeographic research, resource management and marine conservation (Table 1). This thematic approach serves several purposes, including helping to define potential goals and products, prioritizing the raw data needs and tool development, providing a form of synthetic atlas to identify spatial data gaps for future research needs, and facilitating effective outreach and public engagement.

\section{Biodiversity data network}

The OBIS-SEAMAP program and the OBIS network, in general, are examples of a larger community of emerging ocean biodiversity informatics programs and activities (Costello \& Vanden Berghe 2006, in this Theme Section). Ecoinformatics focuses on the development of technologies to enhance the discovery, exchange, and analysis of ecological data (see http:// ecoinformatics.org). In order to facilitate the discovery and exchange of data between programs, the central OBIS facility has adopted the use of the Darwin Core protocol using XML (Extensible Markup Language) and DiGIR (Distributed Generic Information Retrieval: http://digir.sourceforge.net) as a standard Internet exchange language and database access package for search and retrieval of records between participating network data nodes. OBIS-SEAMAP is participating in the OBIS network through the use of DiGIR's client package, thus making its data available to the public through the central OBIS search interface. OBIS, in turn, is a data provider to the Global Biodiversity Information Facility (GBIF), which also uses DiGIR and XML.

\section{Data Mines, Factories, and Pipelines}

Development of the Internet-enabled OBIS-SEAMAP system requires flexible access tools for end users, rapid ingestion of data from providers, and on-the-fly server-to-server data conduits to and from institutional partners for overlay and analysis. These 3 components can be termed, respectively, Data Mines, Factories, and Pipelines (Fig. 1).

The Data Mine allows users to browse, search, map, and download archived biogeographic data. A custom search interface has been created, for taxonomic, attribute, and spatial searches. All datasets may be

Table 1. Potential applications illustrating the utility of the OBIS-SEAMAP (Ocean Biogeographic Information System-Spatial Ecological Analysis of Marine Megavertebrate Animal Populations) system for biogeographic research, resource management, and marine conservation

\begin{tabular}{|c|c|c|}
\hline Theme & Rationale & Examples \\
\hline $\begin{array}{l}\text { Climatological } \\
\text { setting }\end{array}$ & $\begin{array}{l}\text { To illustrate some of the pervasive biogeo- } \\
\text { graphic patterns of species distribution } \\
\text { in the world's ocean }\end{array}$ & $\begin{array}{l}\text { Spatial gradients in community composition } \\
\text { (e.g. onshore-offshore) } \\
\text { Temporal changes in species distributions } \\
\text { (e.g. seasonal migrations) }\end{array}$ \\
\hline $\begin{array}{l}\text { Anomalous } \\
\text { conditions }\end{array}$ & $\begin{array}{l}\text { To document temporal changes in } \\
\text { communities }\end{array}$ & $\begin{array}{l}\text { Interannual shifts in species distributions and com- } \\
\text { munity composition (e.g. El Niño-La Niña conditions) }\end{array}$ \\
\hline Long-term change & $\begin{array}{l}\text { To discriminate between anthropogenic } \\
\text { impacts and natural variability in mega- } \\
\text { vertebrate populations }\end{array}$ & $\begin{array}{l}\text { Population trends in abundance due to anthropo- } \\
\text { genic impacts (e.g. bycatch and overexploitation) } \\
\text { and shifts in population ranges (e.g. climate change) }\end{array}$ \\
\hline $\begin{array}{l}\text { Management of } \\
\text { marine resources }\end{array}$ & $\begin{array}{l}\text { To help delineate important habitats } \\
\text { deserving protection and to determine } \\
\text { national responsibilities for the manage- } \\
\text { ment and conservation of protected species }\end{array}$ & $\begin{array}{l}\text { Important habitats of protected species } \\
\text { (e.g. migration corridors) } \\
\text { Stock structure of megavertebrates } \\
\text { (e.g. distributions, movements) }\end{array}$ \\
\hline Conservation & $\begin{array}{l}\text { To mitigate existing anthropogenic impacts } \\
\text { and to identify additional threats to } \\
\text { protected species }\end{array}$ & $\begin{array}{l}\text { Overlap with potential impacts (e.g. oil and gas } \\
\text { exploration, fisheries effort, and shipping lanes) } \\
\text { Spatial and temporal areas where impacts take } \\
\text { place (e.g. fisheries catch and bycatch) }\end{array}$ \\
\hline
\end{tabular}



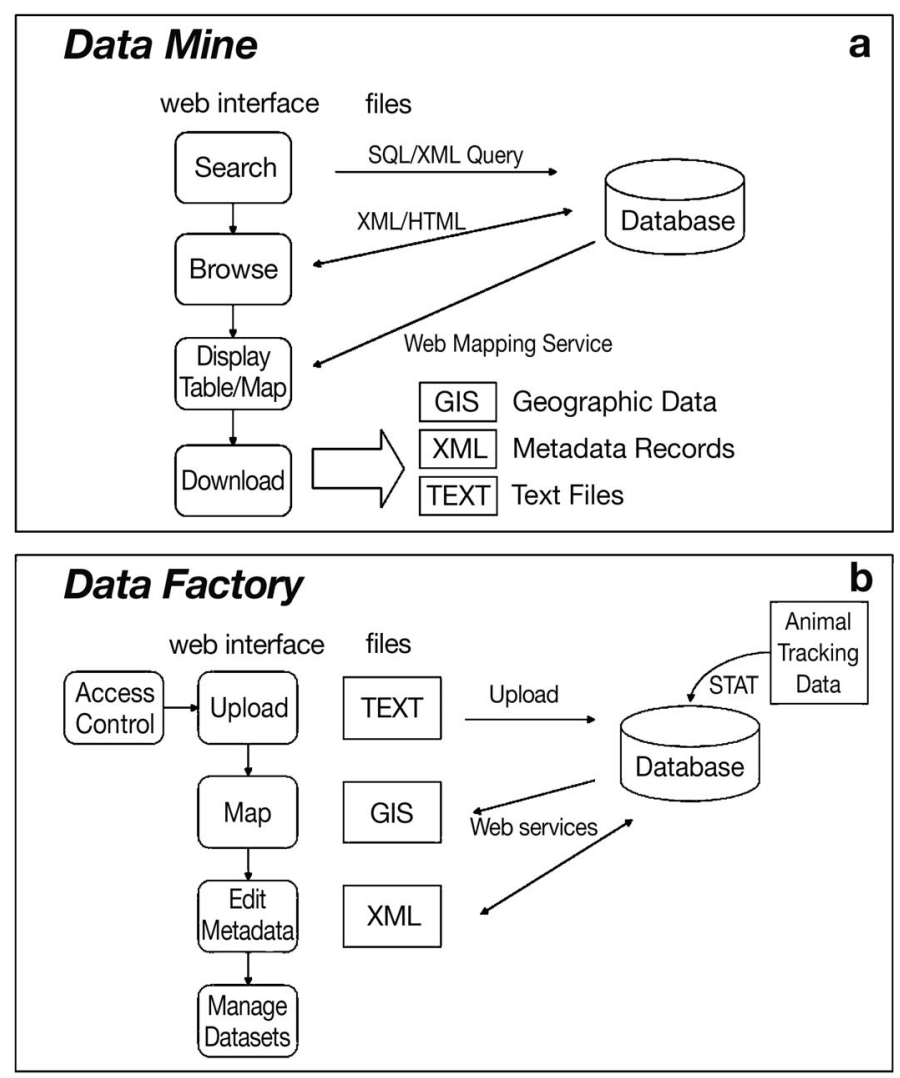

\section{Data Pipeline}

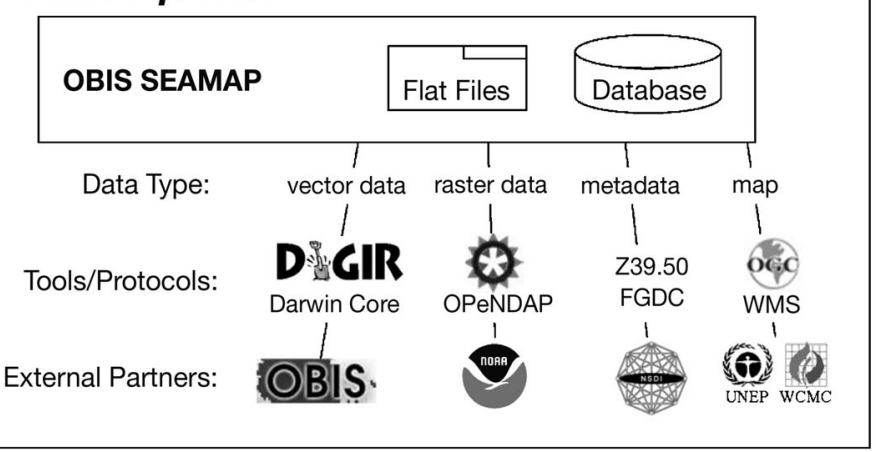

Fig. 1. Conceptualization of the OBIS-SEAMAP services: (a) Data Mine for end users, (b) Data Factory for data providers, and (c) Data Pipeline for server-to-server data exchange

browsed to a detail page, which provides summary information, a species list, FGDC-compliant (www. fgdc.gov) metadata, and original provider contact information. The species list for each dataset links to individual species profiles, which, in turn, contain links back to all relevant dataset detail pages. The online mapping component (described below) allows users to interactively select species, background environmental layers, and spatial extent.
The Data Factory enables data providers and managers to directly upload data into the OBIS-SEAMAP system, match taxonomic codes to species names, enter metadata, and 'publish' their data, making it available to the public. The most common format for data exchange are delimited text files, which can be output from most data-storing programs, and is the preferred format for uploading data. Spatial and temporal extents, along with full taxonomic hierarchies, are calculated for automated creation of FGDCcompliant metadata. A content management system (CMS), or more specifically Plone (http://plone.org), has proven extremely useful in supporting the transfer of all data-related files and content from data providers, as well as providing useful tools within our group for general project management and web content creation.

In addition to local data processing, the OBISSEAMAP system is capable of receiving and processing automated data uploads from the Argos satellite tracking system (Fig. 1b). Automated data upload and processing of satellite tracking provides sophisticated processing tools that are very attractive to potential data providers. The STAT program (Coyne \& Godley 2005), developed by a member of the OBIS-SEAMAP team, provides a prototype of the full functionality that is currently being extended to the OBIS-SEAMAP system.

Finally, the Data Pipelines not only disseminate data to partners, such as to OBIS through DiGIR, but also consume data to create map overlays without storing oceanographic data locally. Using widely adopted protocols and tools, server-to-server Internet communication automates the distribution of information. For example, the OGC Web Mapping Service (WMS) protocol is now used by the OBIS-SEAMAP map server to retrieve date-specific oceanographic images of seasurface temperature, sea heights, and winds on-the-fly from the NASA Jet Propulsion Laboratory's WMS server (http://seablade.jpl.nasa.gov/de.shtml). This allows end users to visualize biological data within an oceanographic context from the OBIS-SEAMAP mapping interface without the need to store a single byte (of the existing terabytes) of oceanographic information.

\section{Flexible, taxonomic database}

Long-term offsite storage and viewing of data specific to individual research projects provide limited benefits if users are forced to use an inflexible database design that does not appropriately reflect the original data. For this reason, OBIS-SEAMAP has adopted a flexible relational database design, whereby a single dataset summary table is linked to multiple 
individual dataset tables. Each dataset table has a subset of common fields with any number of additional fields allowed. Data for common fields across all datasets are easily viewed using a database query, while data specific to an individual dataset are maintained within their own table. The flexibility inherent in this database design provides a complete picture of the entire original dataset, which is further appealing for data providers as an offsite backup option.

Taxonomic data storage presents another interesting challenge, as taxonomic names and hierarchies can change over time. The Integrated Taxonomic Information Service (ITIS) (www.itis.usda.gov) and the partnered Species 2000 Catalogue of Life Programme (www.sp2000.org) represent efforts to provide standard taxonomic nomenclature through web services. OBIS-SEAMAP uses the ITIS program's XML service to match common and scientific names with a taxonomic serial number (TSN). All information, including vernacular names and parent and child taxa can be accessed using this XML service. In the OBISSEAMAP, 'Data Factory' scripts automatically match recorded species names to TSNs, while providing an easy-to-use interface for the provider to search and match any remaining TSNs after a dataset is uploaded. Once the TSN has been obtained, all related information is readily accessible for populating the database and for linking to taxonomic information. For example, the metadata record for each dataset lists the full taxonomic hierarchy, including rank, scientific name, and common name, of all species found in the dataset, in conformance with the FGDC Biological Profile. This task would be extremely time consuming if not for such centralized taxonomic services. Having information taxonomically indexed is especially important for retrieving all query results at higher taxonomic rankings (e.g. phylum, class, order, genus) beyond just the species level.

\section{Internet mapping}

Interactive visualization of geospatial data is now feasible with existing Internet Mapping Services (IMS). The OBIS-SEAMAP team is constantly evaluating emerging open-source and commercial Internet mapping software to select the most robust openstandards applications to meet the needs of the marine user community. The OBIS-SEAMAP mapping interface currently uses a PostgreSQL database, a PostGIS geo-database connector, and the University of Minnesota's MapServer on a Linux operating system platform. This current configuration provides a robust, open-source, and open-standards tool kit that can be emulated by other global or regional information sys- tem projects. The open-standards applications allow for the sharing of data and imagery through web services conforming to OGC and OBIS standards.

While the central OBIS portal facility maintains a mapping interface, OBIS-SEAMAP data providers specifically requested the ability to plot sampling effort and vessel trackline information along with their animal observation data. It is often equally useful to know where animals were not observed as it is to know where they were observed. Many important statistical analyses and ecological models require the explicit sampling effort data (e.g. ship and aircraft track line data) and condition (e.g. Beaufort sea state) for proper calculation. For aerial and boat surveys, data providers requested that a line of cruise effort be shown, and for satellite-tracked animals, an inferred track between known locations.

The OBIS-SEAMAP system currently accommodates sampling effort and telemetry tracking data types. In order to support this type of data across the entire OBIS network, the OBIS schema will need to be expanded. The inclusion of survey effort data will require the identification of beginning and ending coordinates for ship or aircraft search effort tracklines and survey conditions. In addition, the inclusion of telemetry tracking data will require (animal) series identifiers, as well as position quality codes for the interpretation of satellite position data. Representation of tracking data from archival data collectors will also require schema modifications in order to accommodate subsurface, 3-dimensional dive data collected for the animals. All of these additions to the general schema are currently under consideration to allow more general use and exchange of these classes of data. By moving beyond the display of simple point data, OBISSEAMAP encourages the CoML community to provide the necessary standardized effort data required to estimate the distribution and abundance of marine animals.

\section{Future technology trends}

The further development of web service architectures based on common standards (e.g. OPenDAP, OGC, SOAP, Marine XML, Digital Object Identifiers etc.) will allow for increased interoperability between the marine biogeographic observation community and the marine oceanographic observation community. The development of modular scripts for scientific workflow modeling programs (e.g. Kepler, JPL SciFlo, ESRI ModelBuilder etc.) and semantics to intelligently exchange across data schemas will facilitate easier, more comprehensive analysis of marine animals and their dynamic environments. 


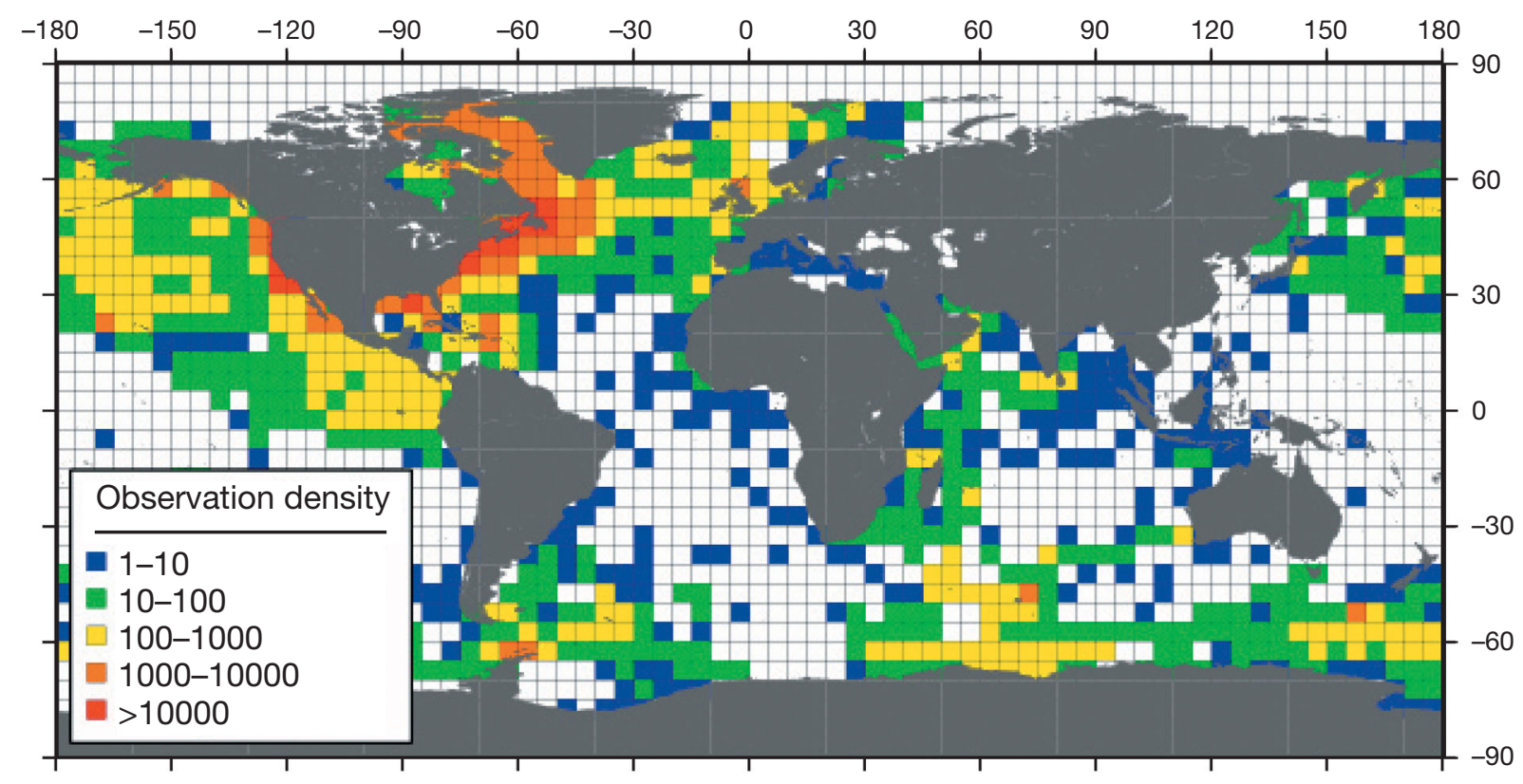

Fig. 2. Spatial density of available marine mammal, sea turtle, and sea bird observations contained in the OBIS-SEAMAP system as of September 20, 2005 in $5 \times 5$ degree cells ( $n=1144248$ observations)

\section{CONCLUSIONS}

The creation of a seamless biogeographic information system, integrated with physical (e.g. ocean physics) and biological (e.g. ocean productivity) datasets, will be the main legacy of the OBIS program (Grassle \& Stocks 1999, Zhang \& Grassle 2002). This interoperable system will place a wealth of physiographic (e.g. habitats) and biogeographic (e.g. species distribution and abundance) data for a broad array of marine organisms and areas of the globe at the fingertips of researchers, students, managers, and policy decision-makers worldwide. This global, interdisciplinary, multi-taxa perspective will provide insights into spatial and temporal changes in ocean productivity, biogeographic patterns, and ecosystem structure around the globe.

The OBIS-SEAMAP digital database of marine mammal, seabird, and sea turtle observations is available online and is fully accessible at: http://seamap. env.duke.edu. At the time of writing (September 2005), the database includes 163 datasets, comprising $>1$ million records, spanning from 1935 to 2005 (Table 2). The website also includes $>100$ species profiles and other background and outreach materials. The global distribution of observation data is depicted in Fig. 2. A web mapping interface allows the interactive display, query, and analysis of this database through the OBIS-SEAMAP homepage.
The diverse array of OBIS-SEAMAP products are already providing marine biogeographers and resource managers with essential information for the study and conservation of marine mammal, bird, and turtle species (e.g. MPA News, March 2004, p. 6). In particular, the web-based query, subset, and data-export tools, and the extensive supporting documentation (e.g. survey methods, ancillary environmental information) have clearly enhanced the utility of the database for scientific research.

OBIS-SEAMAP is also engaging the general public (e.g. educators, students, national governmental organizations) by providing web-based mapping tools to display survey data in conjunction with environmental information and to summarize temporal and spatial patterns of species occurrence in an easily digestible format (e.g. The Society for Conservation Geographic Information Systems e-Newsletter, January 2003, p 5). This outreach is enhancing the public's appreciation for marine ecology and biogeographic patterns by pro-

Table 2. Observation and sampling effort data contained in the OBISSEAMAP data archive listed by survey type (rows) and taxa (columns)

\begin{tabular}{|c|c|c|c|c|c|}
\hline \multirow{2}{*}{$\begin{array}{l}\text { Survey } \\
\text { platform }\end{array}$} & \multicolumn{3}{|c|}{ Number of observations } & \multirow{2}{*}{$\begin{array}{c}\text { Total } \\
\text { observations }\end{array}$} & \multirow{2}{*}{$\begin{array}{l}\text { Number } \\
\text { of datasets }\end{array}$} \\
\hline & Birds & Mammals & Turtles & & \\
\hline Boat & 271909 & 80374 & 1953 & 354236 & 93 \\
\hline Plane & 503605 & 110649 & 4866 & 619120 & 57 \\
\hline Shore & 127759 & 2112 & - & 129871 & 4 \\
\hline Tag & 8797 & 22637 & 9587 & 41021 & 9 \\
\hline Total & 912070 & 215772 & 16406 & 1144248 & 163 \\
\hline
\end{tabular}


viding a database of supporting ecology and natural history information (e.g. species profiles, range maps, and dietary information) necessary to interpret the web-based maps and database summaries.

A clear sign of the continued success of the OBISSEAMAP program will be the increasing participation, collaboration, and data sharing between researchers, managers, and educators around the globe. Progress has already been made with the launch of several meta-analysis projects using or building upon the OBIS-SEAMAP framework. A prime example of the direct application of the OBIS-SEAMAP datasets involves new analyses incorporating data and expertise from a number of OBIS-SEAMAP data providers to predict marine mammal habitats, a project that is supported by the Strategic Environmental Research and Development Program (SERDP).

This research will use spatial analysis techniques to assist the U.S. Navy in planning military readiness exercises in U.S. coastal waters. A similar project, built upon the OBIS-SEAMAP framework, is assessing the global status of sea turtles by looking at spatial and temporal trends in nesting data (Hutchinson et al. 2005). This project, which not only uses OBISSEAMAP data, but also feeds them back into the system, was a major impetus for the addition of new time-series visualization and analysis tools within OBIS-SEAMAP. Both of the marine mammal and sea turtle application projects described above have, in large part, been made possible through the development of the OBIS-SEAMAP data commons.

On the basis of our experience, we contend that the development of large biogeographic data commons will benefit ecological research, not only by compiling the vast datasets required to ask large-scale climatic and conservation questions, but also by acting as a catalyst for the development of the collegiate and collaborative community atmosphere necessary to undertake the large multi-investigator studies required to answer these pressing ecological questions.

Acknowledgements. We thank M. Costello and E. Vanden Berghe for assembling this 'Ocean Biodiversity Informatics' theme section. We are also indebted to the OBIS-SEAMAP steering committee (S. Batten, D. Boersma, J. Croxall, P. Dayton) and the members of the OBIS portal and OBIS International Committee for advice and support. We particularly pay tribute to all of the data providers, especially from the NOAA National Marine Fisheries Services, who have attended the annual OBIS-SEAMAP data provider meetings and contributed large datasets, as well as significant guidance. Funding for this work has been provided by the Alfred

Editorial responsibility: Howard I. Browman (Associate Editor-in-Chief), Storebø, Norway
P. Sloan Foundation, the National Oceanographic Partnership Program, the U.S. Office of Naval Research, the Census of Marine Life, and the Ocean Biogeographic Information System. We also recognize the oceanographic community for its open-access ethos that has made this work possible.

\section{LITERATURE CITED}

Alldredge AL, Bradley DL, Butterworth D, Steele JH (1999) Assessing the global distribution and abundance of marine life: summary of a workshop sponsored by the Sloan Foundation and the Office of Naval Research, January 13-15, Monterey, California. Oceanography 12(3): 41-46

Arzberger P, Schroeder P, Beaulieu A, Bowker G and 5 others (2004) An international framework to promote access to data. Science 303:1777-1778

Ausubel JH (1999) Toward a census of marine life. Oceanography 12(3):4-5

Block BA, Costa DP, Boehlert GW, Kochevar RE (2003) Revealing pelagic habitat use: the tagging of Pacific pelagics program. Oceanol Acta 25:255-266

Bradley DL (1999) Assessing the global distribution and abundance of marine organisms. Oceanography 12:19-20

Costello MJ, Vanden Berghe E (2006) 'Ocean biodiversity informatics: a new era in marine biology research and management. Mar Ecol Prog Ser 316:203-214

Coyne MS, Godley BJ (2005) Satellite Tracking and Analysis Tool (STAT); an integrated system for archiving, analyzing and mapping animal tracking data. Mar Ecol Prog Ser 301:1-7

Decker CJ, O'Dor R (2002) A census of marine life: Unknowable or just unknown? Oceanol Acta 25:179-186

Grassle JF, Stocks KI (1999) A global ocean biogeographic information system (OBIS) for the census of marine life. Oceanography 12(3):12-14

Hutchinson BJ, Mast RB, Pilcher NJ, Seminoff JA (2005) Marine turtle specialist group news: overview of activities for a new year. Mar Turtle Newsl 108:15-17

Levi C, Stone G, Schubel JR (1999) Censusing non-fish nekton. Oceanography 12(3):15-18

McGowan JA (1990) Climate and change in oceanic ecosystems: the value of time series data. Trends Ecol Evol 5(9):293-300

NRC (National Research Council) (1996) Understanding marine biodiversity. National Academy Press, Washington, DC

O'Dor RK (2003) The unknown ocean: the baseline report of the census of marine life research program. Consortium for Oceanographic Research and Education, Washington, DC

Pierott-Bults AC (1997) Biological diversity in oceanic macrozooplankton: more than just counting species. In: Ormond RFG, Gage JD, Angel MV (eds) Marine biodiversity: patterns and process. Cambridge University Press, Cambridge, p 69-93

Stone G, Schubel J, Tausig H (1999) Electronic marine animal tagging: new frontier in ocean science. Oceanography 12(3):24-27

Welch DA, Boehlert GW, Ward BR (2003) POST—-the Pacific Ocean salmon tracking project. Oceanol Acta 25:243-253

Zhang YQ, Grassle JF (2002) A portal for the ocean biogeographic information system. Oceanol Acta 25:193-197

Submitted: September 27, 2005; Accepted: December 2, 2005 Proofs received from author(s): May 26, 2006 